\title{
Mixed Mucus-Secreting and Oncocytic Carcinoma of the Thyroid
}

\author{
Pathologic, Histochemical, Immunohistochemical, and Ultrastructural \\ Study of a Case
}

\author{
Silvia Uccella, MD; Stefano La Rosa, MD; Giovanna Finzi, BD; Silvia Erba, BD; Fausto Sessa, MD
}

\begin{abstract}
- We report a carcinoma that is, to the best of our knowledge, the first case of a mixed mucus-secreting and oncocytic carcinoma of the thyroid. We also describe the histochemical, immunohistochemical, and ultrastructural features of this tumor. A 59-year-old man complaining of severe bone pain and weight loss underwent clinical and radiologic investigations. The studies revealed a nodule in the left thyroid lobe that was "cold" by ${ }^{131}$ I scintiscan and multiple lytic lesions of the skeleton that showed increased uptake by ${ }^{99 \mathrm{~m} T c-S e s t a m i b i}$ scintiscan. Left hemithyroidectomy was performed and the surgical specimen contained a well-circumscribed nodule of $3 \mathrm{~cm}$ in the greatest diameter. Light microscopy showed an oncocytic carcinoma with an area of glandular and papillary proliferation of mucin-producing cells. A double histochemical approach (AIcian blue-periodic acid-Schiff and Alcian blue-high-iron diamine) combined with ultrastructural investigation confirmed the presence of true mucus, ruling out the presence of breakdown products of thyroglobulin. Ultrastructural and immunohistochemical studies, together with clinical findings, excluded a possible metastatic origin of the mucin-producing component.
\end{abstract}

(Arch Pathol Lab Med. 2000;124:1547-1552)

$\mathbf{T}^{\mathrm{h}} \mathrm{e}$ e occasional production of mucinlike substances by cells of primary thyroid neoplasms is a well-known phenomenon ${ }^{1}$; nevertheless, true primitive mucinous (adeno)carcinomas of the thyroid gland are extremely rare and their place in the classification of thyroid tumors is still uncertain. ${ }^{2}$ Mucinous $^{3-5}$ and mucoepidermoid ${ }^{6-9}$ carcinomas of the thyroid have been described and, in addition, mucins have been found in lymph node metastases from papillary carcinomas, ${ }^{10}$ as well as in follicular, ${ }^{11}$ medullary, ${ }^{12,13}$ and undifferentiated ${ }^{14,15}$ cancers. To the best of our knowledge, cases of oncocytic carcinoma of the thy-

\footnotetext{
Accepted for publication March 8, 2000.

From the Department of Clinical and Biological Sciences, Faculty of Medicine, University of Insubria, Varese, Italy (Drs Uccella, Erba, and Sessa) and the Service of Pathology, Ospedale di Circolo, Varese, Italy (Drs La Rosa and Finzi).

Reprints: Fausto Sessa, MD, Servizio di Anatomia Patologica, Ospedale di Circolo, Viale Borri, 57 I-21100, Varese, Italy (e-mail: Anapat@ospedale.varese.it).
}

roid showing mucin production have never been described.

Oncocytic carcinoma of the thyroid gland, also known as Hürthle-cell carcinoma, is a malignant tumor exclusively or predominantly composed of oncocytes (over $75 \%$ of cells), which are cells showing granular cytoplasmic eosinophilia and a "swollen" appearance resulting from mitochondrial accumulation. These tumors account for $2 \%$ to $3 \%$ of all thyroid cancers ${ }^{2}$ and seem to behave in a more aggressive fashion than other well-differentiated thyroid carcinomas. . $^{17,18}$

In this study we describe the clinical and pathologic features of an oncocytic carcinoma of the thyroid showing an area of mucinous differentiation. We designated this tumor a "mixed mucus-secreting and oncocytic carcinoma."

\section{REPORT OF A CASE}

A 59-year-old man presented in February 1998 with severe bone pain, localized primarily to the cervical and thoracic spine and chest wall. The patient reported a weight loss of $13 \mathrm{~kg}$ in the last few months. Radiographic examination of the skeleton showed collapse of the third dorsal vertebra and multiple osteolytic lesions in other vertebrae, ribs, sternum, pelvic bones, and femurs. Magnetic resonance imaging and ${ }^{99 \mathrm{~m}}$ Technetium-diphosphonate scintiscan of the whole skeleton were suggestive of secondary metastasis of an occult malignancy. On physical examination, a thyroid nodule was found in the left lobe. Ultrasonography identified a hypodense lesion of $3 \mathrm{~cm}$ in the greatest diameter that did not trap the tracer during an ${ }^{131}$ I scintiscan. Fine needle aspiration was performed and the cytologic specimens were highly cellular and composed of oncocytic cells. Ultrasound study of the abdomen and pelvis was also performed and the only significant finding was a hypodense subcapsular bilobar area of the prostate; the biopsy of this lesion was diagnostic for atypical acinar hyperplasia with a microfocus of a moderately differentiated prostatic adenocarcinoma. The patient's thyroid function was normal (thyroxin, $2.3 \mathrm{pmol} / \mathrm{L}$; thyroid-stimulating hormone, $1.3 \mathrm{IU} / \mathrm{L})$, whereas serum thyroglobulin $(726 \mu \mathrm{g} / \mathrm{L}$; normal, $10-20 \mu \mathrm{g} / \mathrm{L}$ ) and carcinoembryonic antigen (CEA, $>70$ $\mu \mathrm{g} / \mathrm{L}$; normal, $<5 \mu \mathrm{g} / \mathrm{L}$ ) levels were elevated. Serum prostatespecific antigen (PSA) was slightly elevated $(10.3 \mathrm{ng} / \mathrm{mL}$; normal, $<4 \mathrm{ng} / \mathrm{mL}$ ), but the PSA ratio was normal (0.09).

The patient underwent left hemithyroidectomy. After surgery, additional computerized tomographic scans were negative for metastatic lesions in the lungs, liver, and other internal organs. Scintigraphy with ${ }^{99 \mathrm{~m} T c-S e s t a m i b i}$ revealed uptake of the tracer in the mediastinum and left hemithorax, corresponding to oste- 


\begin{tabular}{|llll|}
\hline & \multicolumn{1}{c|}{ Antibodies and antisera employed } & \\
\hline \multicolumn{1}{|c}{ Antibody or Antiserum } & P or M (clone) & \multicolumn{1}{c|}{ Source } \\
\hline Mitochondrion & $\mathrm{M}(113-1)$ & $1 / 100$ & Dilution \\
Thyroglobulin & $\mathrm{P}$ & Undiluted & Ortho, Raritan, NJ \\
Carcino-embryonic antigen & $\mathrm{M}$ (B01-94-11M) & Undiluted & BioGenex \\
Calcitonin & $\mathrm{M}$ (SILVIA) & $1 / 200$ & Ortho \\
Chromogranin A & $\mathrm{M}$ (Phe 5) & $1 / 50$ & Enzo, New York, NY \\
Prostatic specific antigen & $\mathrm{P}$ & Undiluted & Dako, Copenhagen, DK \\
Pepsinogen II & $\mathrm{P}$ & $1 / 2000$ & Gift of Samlofft \\
E-cathepsin & $\mathrm{P}$ & $1 / 2000$ & Gift of Samlofft \\
Salivary amylase & $\mathrm{P}$ & $1 / 100$ & Biogensis, Bournemouth, UK \\
Ki-67 & $\mathrm{M}(\mathrm{MIB}-1)$ & $1 / 50$ & Ylem, Roma, I \\
p53 & $\mathrm{M}$ (DO7) & $1 / 1000$ & Dako \\
\hline
\end{tabular}

* $\mathrm{P}$ indicates polyclonal; $\mathrm{M}$, monoclonal.

† Kind gift of Dr I. M. Samloff, Veterans Administration Medical Center, Sepulveda, Calif.

olytic lesions of the ribs and sternum. One month after hemithyroidectomy, external radiotherapy was started because of bone metastases. No regression occurred and the patient died in July 1998. Postmortem examination was not carried out.

\section{MATERIALS AND METHODS}

Samples of the tumor were fixed in buffered formalin (formaldehyde $4 \% \mathrm{wt} / \mathrm{vol}$ acetate buffer $0.005 \mathrm{~mol} / \mathrm{L}$ ) and routinely processed in paraffin wax. Sections were stained with hematoxylin-eosin (H\&E), Alcian blue ( $\mathrm{pH}$ 2.5)-periodic acid-Schiff (ABPAS), and Alcian blue ( $\mathrm{pH}$ 2.5)-high-iron diamine (AB-HID).

Immunohistochemistry was performed using the antibodies and antisera listed in the Table. Antithyroglobulin serum was employed as a thyroid marker and the antimitochondrial antibody was used to assess the oncocytic nature of neoplastic cells. Anticalcitonin and anti-chromogranin A antibodies were employed to exclude a medullary thyroid carcinoma. Antibodies directed against prostatic-specific antigen, pepsinogen II, cathepsin $\mathrm{E}$, and salivary amylase were used to exclude the possibility that the mucinous area represented a metastasis from a primary tumor in the prostate, digestive tract, or salivary glands, respectively. In addition, the anti-carcinoembryonic antigen antibody was used to evaluate the mucin-producing component. Anti-Ki67 and anti-p53 monoclonal antibodies were employed to investigate the proliferative index and p53 nuclear accumulation in the 2 different components. For immunohistochemical stains, 3- $\mu \mathrm{m}$ sections mounted on poly-L-lysine-coated slides were used. After hydration through graded alcohols to water, endogenous peroxidase activity was inhibited with 3\% hydrogen peroxide for 10 minutes. Primary antibody (Table) incubations were performed at $4^{\circ} \mathrm{C}$ for 18 hours followed by the avidin-biotin complex technique. ${ }^{19}$ Immunoreactions were developed using $0.03 \%$ 3,3'-diaminobenzidine tetrahydrochloride. Sections immunostained with antibodies directed against salivary amylase and p53 were pretreated with $0.001 \mathrm{~mol} / \mathrm{L}$ citrate buffer $(\mathrm{pH}$ 6) for 10 minutes in a microwave oven at $600 \mathrm{~W}$. Sections stained with anticalcitonin antibody were pretreated with $0.05 \%$ trypsin in $0.05 \mathrm{~mol} / \mathrm{L}$ trisbuffered saline ( $\mathrm{pH}$ 7.4). Sections stained for Ki-67 (MIB-1) were pretreated with $0.05 \%$ trypsin in $0.05 \mathrm{~mol} / \mathrm{L}$ tris-buffered saline ( $\mathrm{pH}$ 7.4) before microwave treatment.

The Ki-67 (MIB-1) proliferative index was determined by counting the number of MIB-1-positive cells in a minimum of 500 neoplastic cells in both oncocytic and mucinous areas. The percentage of p53-immunoreactive cells was semiquantitatively evaluated.

For ultrastructural examination, formalin-fixed samples of the neoplasm were used. The specimens were postfixed in $1 \%$ osmium tetroxide (Merck, Darmstadt, Deutschland) in $0.1 \mathrm{~mol} / \mathrm{L}$ cacodylate buffer $\mathrm{pH} 7.3$ (Merck), dehydrated in ethanol, and embedded in Epon-Araldite (Epon 812, Durcupan ACM: Fluka, Buchs, Switzerland; DDSA: Polysciences, Warrington, Pa, USA; DMP-30: Serva, Heidelberg, Deutschland). Ultrathin sections were cut with a diamond knife, stained with uranyl acetate (Poly- sciences) and lead citrate (Merck), and examined using a Zeiss EM10 transmission electron microscope.

\section{RESULTS \\ Pathologic Findings}

At gross examination, a well-circumscribed encapsulated nodule measuring $3 \mathrm{~cm}$ in the greatest dimension was found in the left hemithyroidectomy specimen. The tumor showed a solid tan aspect with multiple foci of hemorrhage. A peripheral poorly defined whitish area of approximately $1 \mathrm{~cm}$ in diameter was also seen within the nodule.

Microscopically, the lesion was encapsulated and revealed to be composed primarily of polygonal cells with abundant granular eosinophilic cytoplasm, showing the classic features of oncocytic (Hürthle) cells, arranged in a microfollicular and solid/trabecular pattern (Figure 1). The nuclei were round with finely dispersed chromatin and evident nucleoli, eccentrically located. Mitotic figures were extremely rare (1 figure per 30 high-power fields). Focal capsular infiltration and vascular neoplastic emboli were observed in the surrounding nonneoplastic thyroid, suggesting malignancy. In samples taken from the whitish area, papillary and glandular structures formed by columnar cells with basophilic cytoplasm and basally located nuclei were seen (Figure 1). A strongly alcianophilic material was seen within the glandular lumens and spaces among papillae. Alcian blue staining was also observed in intracytoplasmic vacuoles and at the apical cell borders (Figure 2), whereas no HID stain was observed. The nuclei showed some pleomorphism and were larger and more irregular in shape than those seen in the oncocytic zone. The chromatin was clumped, giving the nuclei a clear vesiculated appearance, and some elements had multiple eosinophilic nucleoli. The mitotic index in this area was 6 mitoses per $10 \times 400$ high-power fields. This "mucinous" area seemed to have expanding edges, compressing the surrounding neoplastic parenchyma; however, in several areas, continuity with the typical oncocytic proliferation was evident.

\section{Immunohistochemistry}

All neoplastic cells, both those in the oncocytic zone and those in the papillary and glandular area, were immunoreactive for antimitochondrial antibody; in the former cells, immunostaining was very strong with a crowded granular cytoplasmic pattern, whereas in the latter cells, it was granular and dotlike (Figure 3). Weak and zonal 


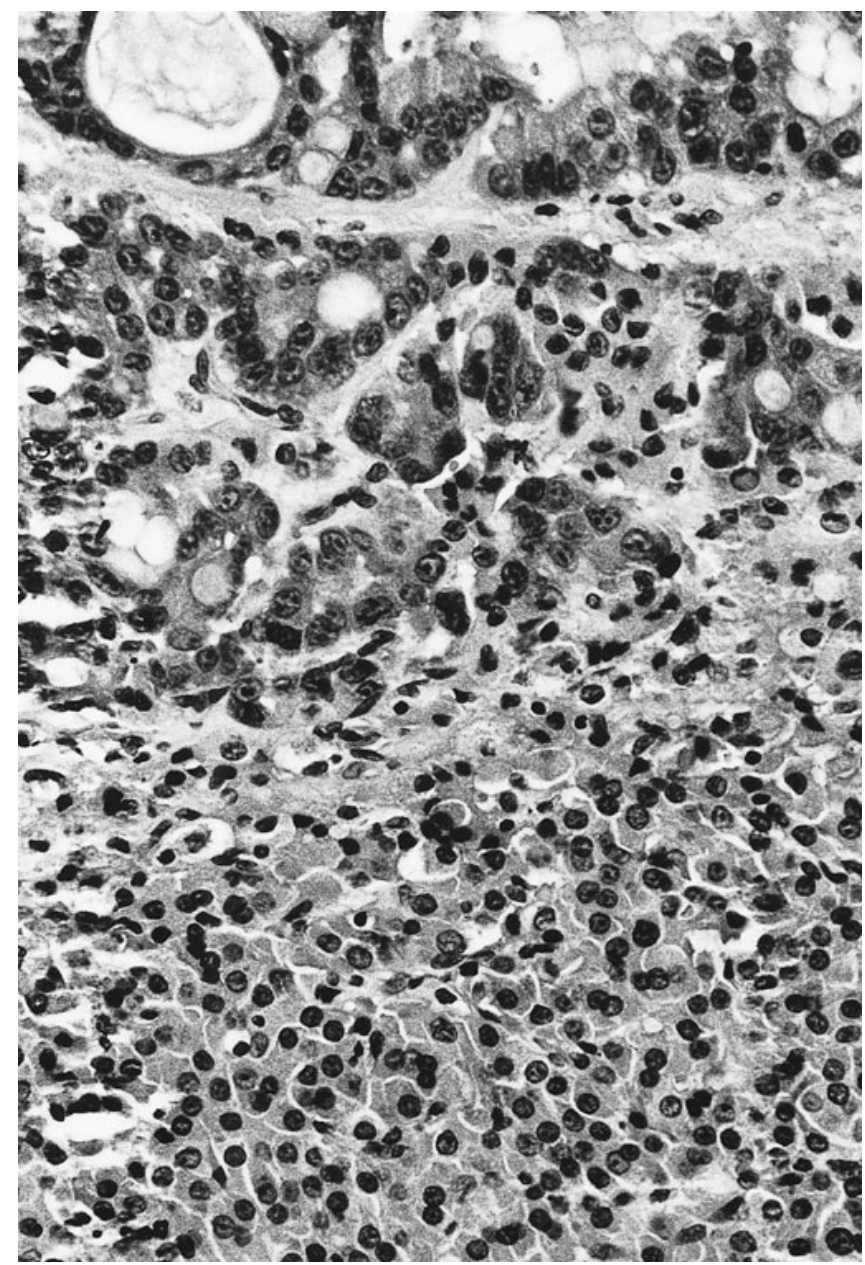

Figure 1. Mixed mucus-secreting and oncocytic carcinoma of the thyroid showing an oncocytic solid component (bottom) and mucin-producing glandular structures (top) (hematoxylin-eosin, original magnification $\times 200)$.

immunoreactivity for thyroglobulin was only seen in the typical oncocytic cells, whereas an intense expression of CEA was exclusively seen in the mucinous elements. No staining was noted using antibodies directed against calcitonin and chromogranin A, excluding the possibility of a medullary carcinoma of the thyroid. Antibodies or antisera directed against PSA, pepsinogen II, E-cathepsin, and salivary amylase gave negative immunoreactions, ruling out metastasis from the prostate, digestive tract, and salivary glands.

The Ki-67 (MIB-1) proliferative index was lower in the oncocytic component $(2 \%)$ than in the mucinous area $(54 \%)$ of the tumor (Figure 4$)$. Nuclear p53 accumulation was found in a few scattered oncocytes (less than 1\%), whereas it was detected in about $40 \%$ of mucin-producing cells (Figure 5).

\section{Electron Microscopy}

Ultrastructural examination was performed on specimens obtained from both the oncocytic and the mucinous areas of the tumor. Oncocytic cells had nuclei with some indentations; the chromatin was moderately dispersed and the nucleoli were generally small and eccentric. The cytoplasm was typically packed with numerous mitochondria with few residual organelles (Figure 6). In the mucin-

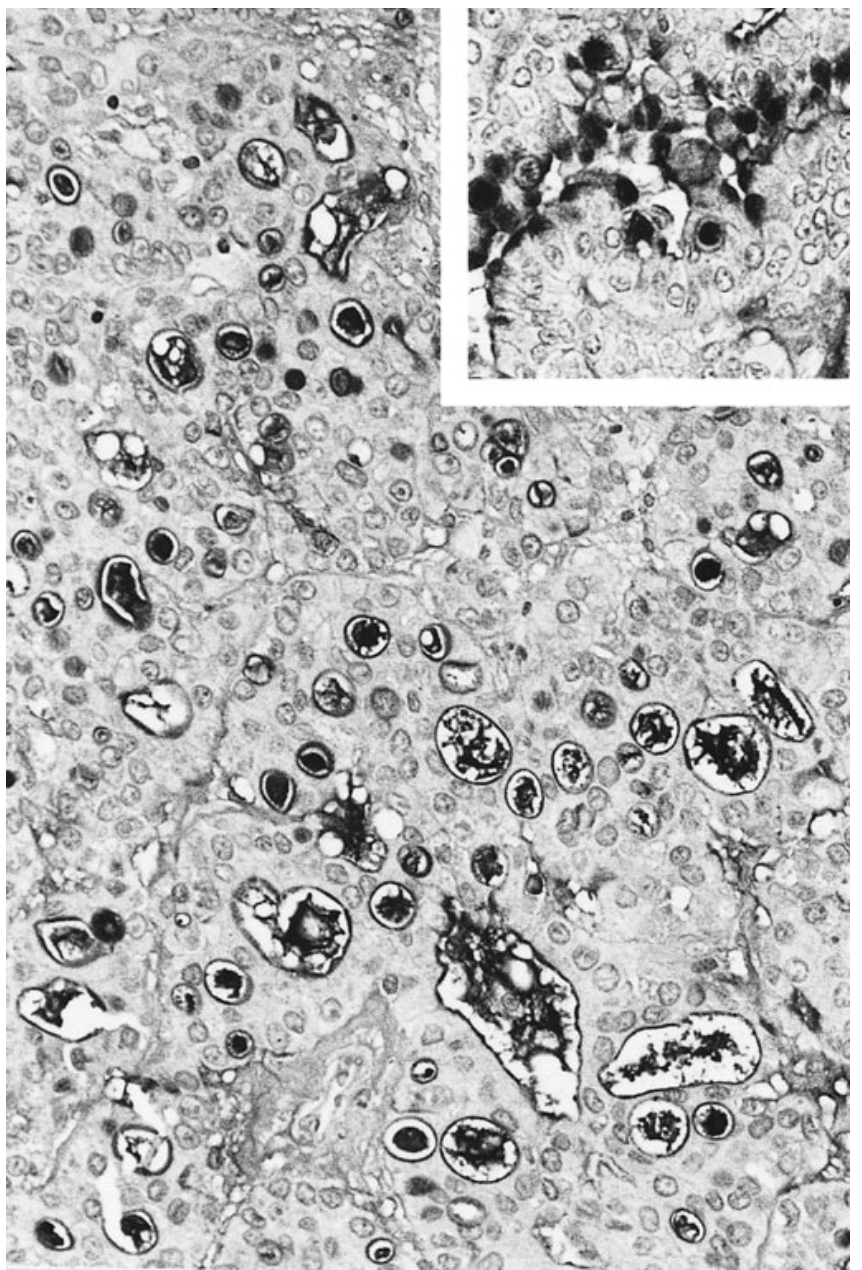

Figure 2. Mucus-secreting area showing Alcian blue staining in glandular lumina and in the cytoplasm of cells (inset) (Alcian-blue/PAS, original magnification $\times 200$ ).

ous area, neoplastic cells showed basally located, deeply indented nuclei, with clumped chromatin primarily located along the nuclear membrane. Nucleoli were prominent and often multiple. These cells had apical borders presenting short and irregular microvilli. Numerous mucinous granules were observed below the secretory pole and these granules sometimes exhibited electron-dense cores (Figure 7). Moreover, a large number of mitochondria were also present in the cytoplasm of these cells, although they were less numerous than in the oncocytic area. No colloid material or colloid droplets were seen.

\section{COMMENT}

Although primary mucinous (adeno)carcinomas of the thyroid have been described, ${ }^{3-5}$ their recognition as a true entity is still a matter of debate. In contrast, mucin production by cells of several thyroid neoplasms is a wellknown phenomenon, as previously reported. . $^{1,2,10-15}$

A mucin-producing neoplasm within the thyroid poses at least 2 problems: the first problem concerns the primary or metastatic nature of the tumor; the second problem concerns the difficulty of assessing whether the mucinlike material observed in the context of the neoplasm is true mucus. Metastatic involvement of the thyroid from distant malignancies, such as carcinomas of the lung, gastrointes- 


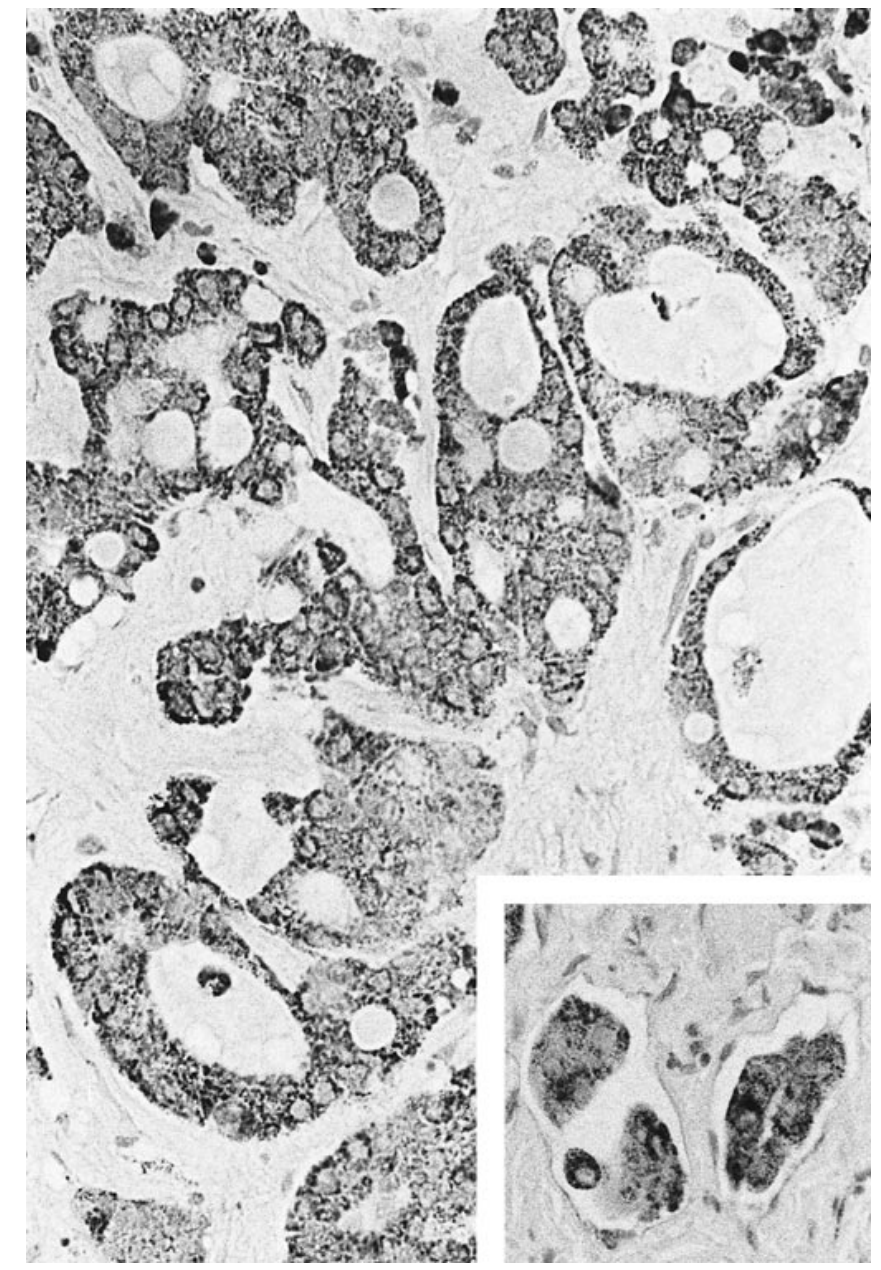

Figure 3. Mitochondrion immunoreactivity in neoplastic cells of the mucus-secreting component and in neoplastic emboli within the tumor capsule (inset) (avidin-biotin complex technique with hematoxylin counterstain, original magnification $\times 200$ ).

tinal tract, kidney, and skin, has been reported. ${ }^{2,20}$ Authors describing primary mucinous tumors of the thyroid have ruled out a metastatic nature by considering clinical data, ${ }^{3}$ by evaluating follow-up data, ${ }^{5}$ or by detecting mucins together with colloid ${ }^{11}$ or thyroglobulin ${ }^{4}$ in these neoplasms. The diagnosis of "mucin-secreting tumor" of the thyroid has traditionally relied upon apparent positivity of various histochemical methods for detection of mucinlike substances, commonly employed for the study of either gastrointestinal or bronchial mucin-secreting epithelia, such as periodic acid-Schiff, Alcian blue, mucicarmine, and other methods. These techniques should be employed and interpreted with caution in the study of thyroid tumors, as they may detect breakdown products of thyroglobulin and colloid and not true mucinlike substances. ${ }^{21}$

We considered the possibility that our tumor could be a thyroid metastasis from a cancer located in another site, namely in the prostate, where a biopsy disclosed a microfocus of adenocarcinoma. We first ruled out this possibility based on the low serum levels of PSA, followed by the lack of PSA immunoreactivity in the thyroid neoplastic tissue. In addition, the extensive imaging examination the patient underwent failed to reveal any possible site for a primary malignancy other than the thyroid. Furthermore, the positive result of the ${ }^{99 \mathrm{~m}} \mathrm{Tc}$-Sestamibi scintiscan, which

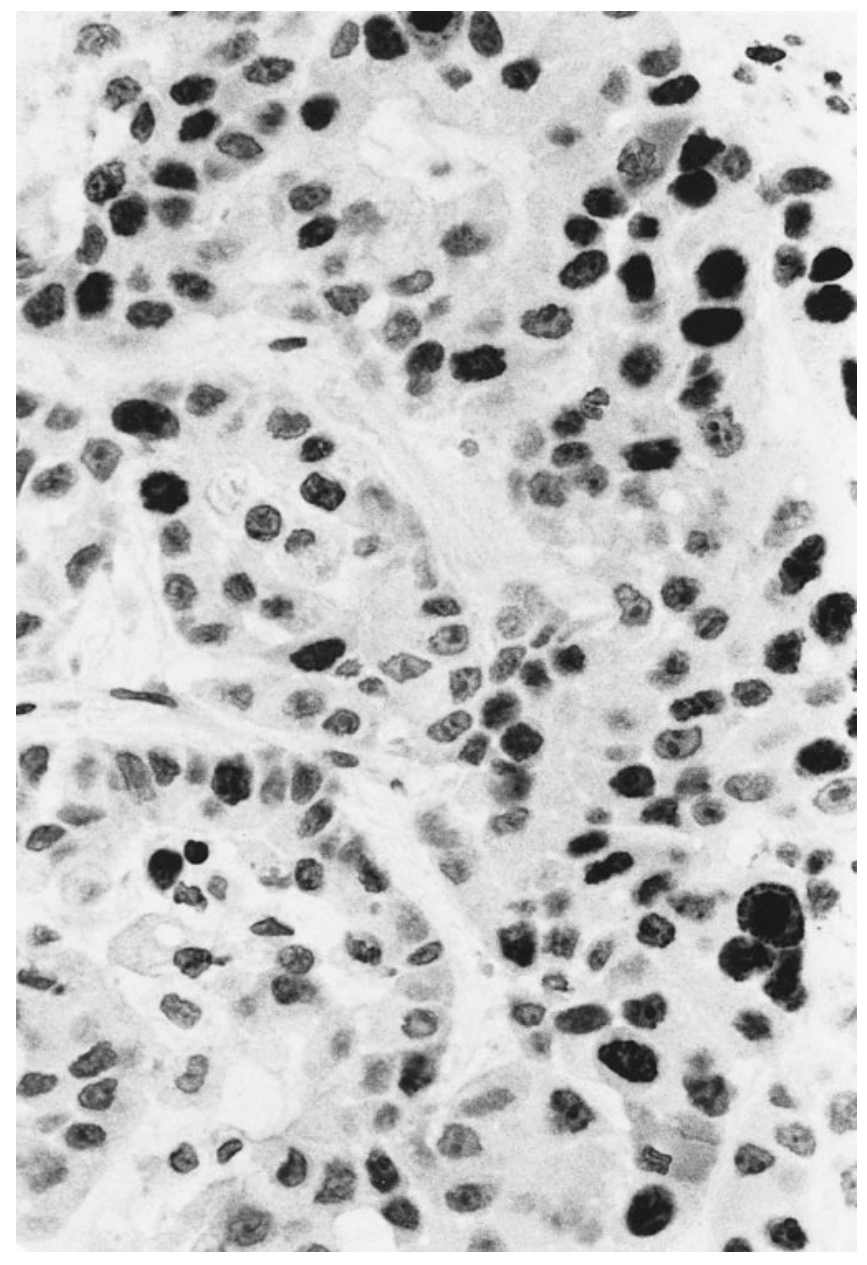

Figure 4. Immunoreactivity for Ki-67 (MIB-1) in mucin-secreting cells (avidin-biotin complex technique with hematoxylin counterstain, original magnification $\times 400)$.

has been reported to identify Hürthle cell tumors and their metastases, ${ }^{22}$ as well as the raised thyroglobulin levels, supported the likelihood that bone metastases could be attributed to the thyroid oncocytic carcinoma. On the other hand, immunohistochemistry showed no positivity for PSA, pepsinogen II, E-cathepsin, and salivary amylase, thus ruling out primaries from prostate, digestive tract, and salivary glands. In addition, the absence of immunoreactivity for chromogranin A and calcitonin excluded the possibility of a medullary thyroid carcinoma, which has been reported to have mucinous differentiation. ${ }^{13}$ In contrast, both the classic oxyphilic and the mucin-producing components stained strongly for antimitochondrial antibody, which recognize oncocytes. ${ }^{23}$ This pattern demonstrated that both areas were rich in mitochondria and suggested that the 2 areas should be considered as 2 different aspects of the oncocytic carcinoma. Ultrastructural examination supported this hypothesis, showing that neoplastic cells of the mucinous area were very rich in mitochondria and suggesting that this component could be considered as a mucinous differentiation of the Hürthle cell carcinoma.

The lack of immunoreactivity for thyroglobulin in the mucinous component, at first sight, argues against a thyroid primary. However, several primary thyroid tumors have been reported to be thyroglobulin-negative or weak- 


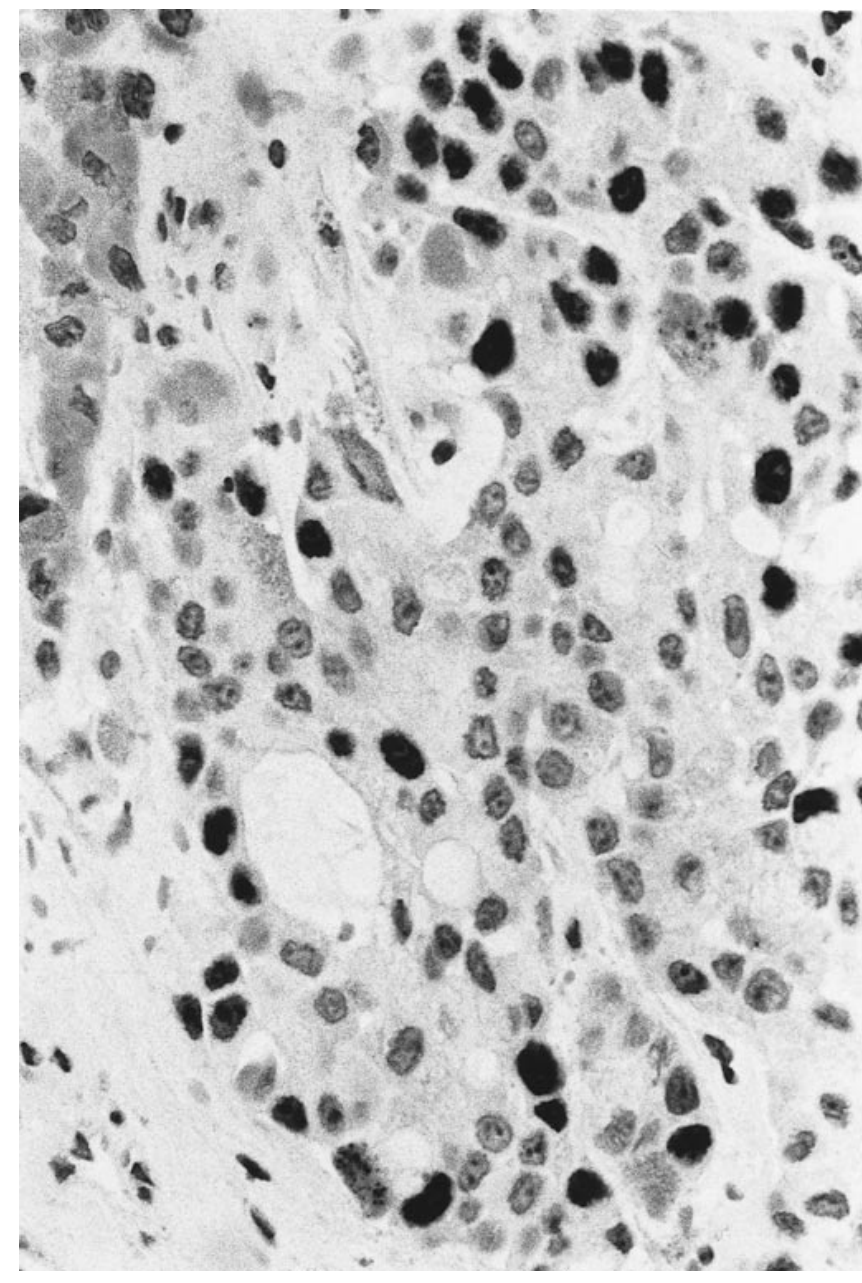

Figure 5. Immunostaining for p53 in the mucinous component of the tumor (avidin-biotin complex technique with hematoxylin counterstain, original magnification $\times 400)$.

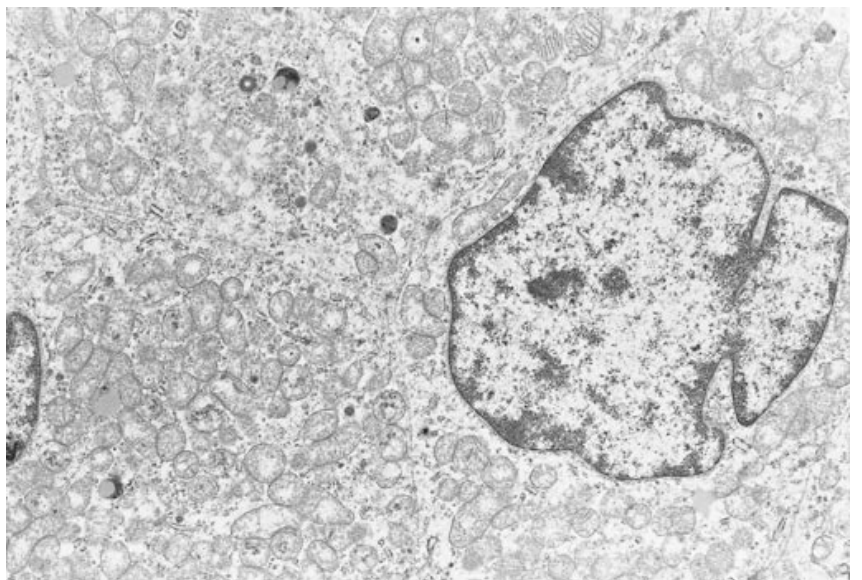

Figure 6. Cells of the oncocytic component showing cytoplasm packed with mitochondria (uranyl acetate-lead citrate, original magnification $\times 28000$ ).

ly positive. ${ }^{3,5,6,8,24}$ It is possible that thyroglobulin production decreases as the follicular cells gain mucinous differentiation. Furthermore, it has been suggested that oncocytic tumors of the thyroid produce only small amounts of thyroglobulin..$^{25-27}$ So, if the mucinous aspects of our neoplasm are to be considered as a mucin-producing differentiation of a Hürthle-cell carcinoma, the lack of thyroglobulin immunoreactivity is not surprising. Immunoreaction for CEA was observed in the mucin-producing area of the present case. Among primary tumors of the thyroid, CEA-positivity is a feature of medullary carcinomas, ${ }^{2}$ but as noted previously, this diagnosis was excluded by immunohistochemical findings. However, sporadic cases of Hürthle-cell carcinoma and anaplastic carcinoma of the thyroid have been found to produce CEA. ${ }^{26-29}$ Moreover, a case of mucin-producing poorly differentiated adenocarcinoma of the thyroid has been reported to be CEA-positive. ${ }^{15}$ Finally, intraductal oncocytic papillary mucinous tumors have been described in the pancreas and some of them were CEA-positive. . $0,31^{2}$

The study of the mucinous component of the neoplasm
Figure 7. Apical pole of a mucin-secreting cell. Note microvilli protruding in the gland lumen, mucinous secretory granules (upper right), and mitochondria (bottom left) (uranyl acetate-lead citrate, original magnification $\times 44800)$.

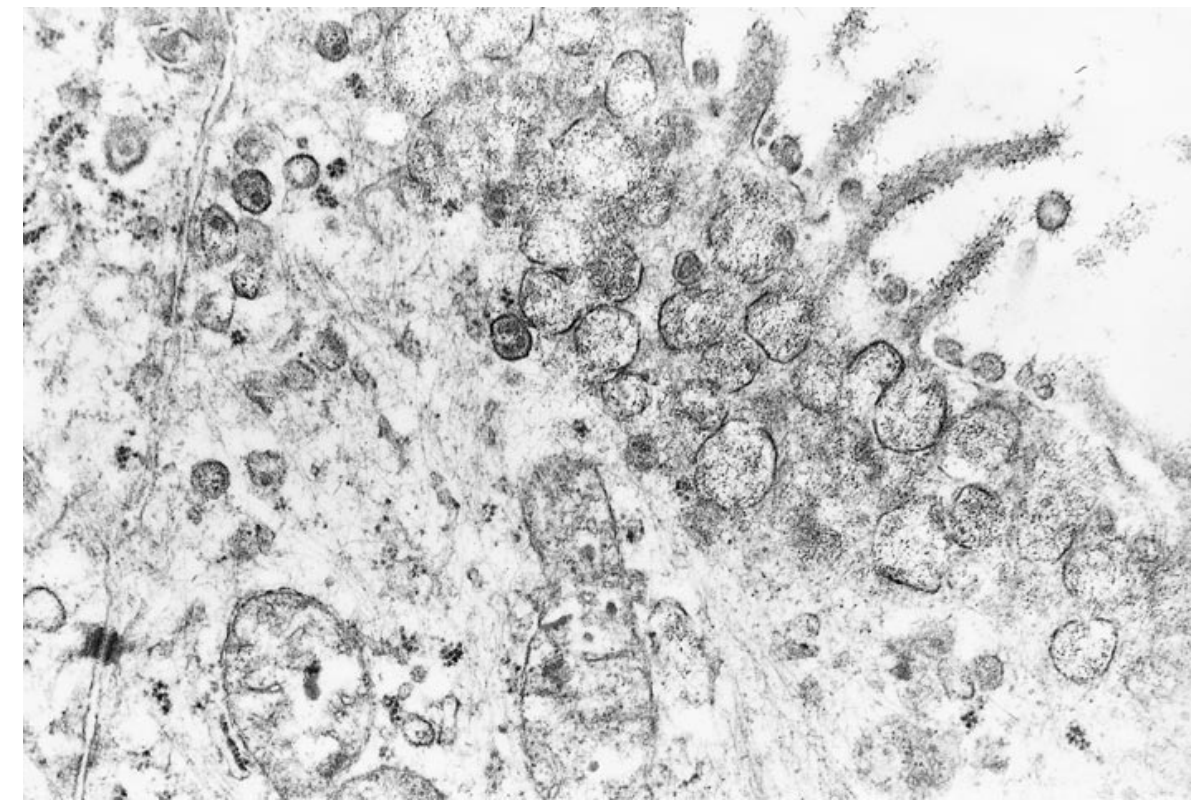


was performed using 2 stains: (1) the AB-PAS stain, which distinguishes between acid mucins stained blue by $A B$ and neutral mucins stained magenta by PAS; and (2) the AB-HID stain, which differentiates sulfomucins stained brownish by HID and sialomucins stained blue by $\mathrm{AB}$. This double approach allowed us to evaluate the whole spectrum of the possible mucin secretion. Considering that breakdown products of thyroglobulin are neutral glycoproteins that are stained by PAS, PAS staining in thyroid tumors should not suggest true mucus production. ${ }^{21}$ In our case, we found strong alcianophilia in both extra- and intracellular spaces, with no positivity for other stains with the exception of some extracellular PAS-positivity. Such results favor genuine mucin production. The absence of PAS staining indicates that the mucin did not arise from the breakdown of thyroglobulin. Thus, we believe that it is correct to define this component of the tumor as "mucus-secreting." In addition, HID staining, which is a typical feature of colorectal and biliopancreatic adenocarcinomas, was not found in our tumor. This helps us to exclude a metastatic nature of the mucinous component. Ultrastructural study showed numerous mucinous granules with an electron-dense core. This finding gave further confidence to the hypothesis that the mucinlike material observed at light microscopy was true mucus produced by neoplastic cells of the glandular and papillary component of the tumor.

The histogenesis of mucin-producing neoplasms of the thyroid gland has been a debated and is a controversial issue. Diaz-Perez et $\mathrm{al}^{5}$ have suggested that the mucinous thyroid tumor they described could have originated from thyroglossal vestiges, because thyroglossal cysts or sinus are lined by ciliated pseudostratified respiratory type cells, squamous cells, and mucus-secreting columnar cells. Rhatigan et $\mathrm{al}^{8}$ speculated that salivary gland remnants trapped in the developing thyroid were responsible for their case of mucoepidermoid cancer. The concurrent production of mucinlike substances and thyroglobulin in some tumors"11,32,33 has suggested the so-called "dual differentiation" hypothesis, ${ }^{33}$ which assumes differentiation of a primitive endodermal cell along both an endocrine and a mucus-secreting line. This phenomenon is observed in other endodermal-derived organs, such as the stomach and intestine. ${ }^{34}$ However, none of these hypothesis has been definitely proved.

The neoplasm that we have described was very aggressive from a clinical and biological point of view, resulting in diffuse bone metastases and death within 5 months of diagnosis. This dramatic course may be related to the presence of the mucinous component, as suggested by the literature concerning "pure" mucinous carcinomas and mucoepidermoid carcinomas of the thyroid. ${ }^{3,4,6,8}$ These data lead to the conclusion that these tumors are probably more aggressive than other more common thyroid carcinomas lacking mucin production. According to this hypothesis, the mucinous component of our tumor had the features of a highly malignant neoplasm, showing marked cytologic atypia, high mitotic and Ki-67 indices, and p53 nuclear accumulation.

In conclusion, this report represents the first description of a mucin-producing oncocytic carcinoma of the thyroid that was biologically aggressive and led to a poor clinical outcome.
This study was supported by a grant of the University of Insubria, Varese, Italy.

\section{References}

1. Mlynek ML, Richter HJ, Leder LD. Mucin in carcinomas of the thyroid. Cancer. 1985;56:2647-2650.

2. Rosai J, Carcangiu ML, De Lellis RA. Atlas of Tumor Pathology. Tumors of the Thyroid Gland. 3rd ed. Washington, DC: Armed Forces Institute of Pathology; 1992.

3. Sobrinho-Simões M, Nesland JM, Johannessen JV. A mucin-producing tumor in the thyroid gland. Ultrastruct Pathol. 1985;9:277-281.

4. Sobrinho-Simões M, Stenwig AE, Nesland JM, Holm R, Johannessen JV. A mucinous carcinoma of the thyroid. Pathol Res Pract. 1986;181:464-469.

5. Diaz-Perez R, Quiraz H, Nishiyama RH. Primary mucinous adenocarcinoma of the thyroid gland. Cancer. 1976;38:1323-1325.

6. Franssilla KO, Harach HR, Wasenius VM. Mucoepidermoid carcinoma of the thyroid. Histopathology. 1984;8:847-860.

7. Katoh R, Sugai T, Ono S. Mucoepidermoid carcinoma of the thyroid gland. Cancer. 1990;65:2020-2027.

8. Rhatigan RM, Roque JL, Bucher RL. Mucoepidermoid carcinoma of the thyroid gland. Cancer. 1977;39:210-214

9. Sambade C, Franssilla K, Basìlio-de-Oliveira CA, Sobrinho-Simões M. Mucoepidermoid carcinoma of the thyroid revisited. Surg Pathol. 1990;3:271-280.

10. Chan JKC, Tse CCH. Mucin production in metastatic papillary carcinoma of the thyroid. Hum Pathol. 1988;19:195-200.

11. Deligdisch L, Subhani Z, Gordon RE. Primary mucinous carcinoma of the thyroid gland. Report of a case and ultrastructural study. Cancer. 1980;45:25642567.

12. Fernandes BJ, Bedard YC, Rosen I. Mucus-producing medullary carcinoma of the thyroid gland. Am J Clin Pathol. 1982;78:536-540.

13. Zaatari GS, Saigo PE, Huvos AG. Mucin production in medullary carcinoma of the thyroid. Arch Pathol Lab Med. 1983;107:70-74.

14. Carcangiu ML, Steeper T, Zampi G, Rosai J. Anaplastic thyroid carcinoma. A study of 70 cases. Am J Clin Pathol. 1985;83:135-158.

15. Mizukami Y, Nakajima H, Annen Y, Michigishi T, Nonomura A, Nakamura S. Mucin-producing poorly differentiated adenocarcinoma of the thyroid. A case report. Pathol Res Pract. 1993;189:608-612.

16. Tallini G. Oncocytic tumours. Virchows Arch. 1998;433:5-12.

17. DeGroot LJ, Kaplan EL, Shukla MS, Salti G, Straus FH. Morbidity and mortality in follicular thyroid cancer. J Clin Endocrinol Metab. 1995;80:2946-2953.

18. Har-el G, Hadar T, Segal K, Levy R, Sidi J. Hürthle cell carcinoma of the thyroid gland. A tumor of moderate malignancy. Cancer. 1986;57:1613-1617.

19. Hsu SM, Raine L, Fanger H. Use of avidin-biotin-peroxidase complex (ABC) in immunoperoxidase technique. J Histochem Cytochem. 1981;25:577589.

20. Czech JM, Lichtor TR, Carney JA, van Heerden JA. Neoplasms metastatic to the thyroid gland. Surg Gynecol Obstet. 1982;155:503-505.

21. Rigaud C, Bogomoletz WV. "Mucin-secreting" and "mucinous" primary thyroid carcinomas: pitfalls in mucin histochemistry applied to thyroid tumours. J Clin Pathol. 1987;40:890-895.

22. Vattimo A, Bertelli P, Cintorino M, Burrani L, Volterrani D, Vella A. Identification of Hürthle cell tumor by single-injection, double-phase scintigraphy with technetium-99m-Sestamibi. / Nucl Med. 1995;36:778-782.

23. Papotti M, Gugliotta P, Forte G, Bussolati G. Immunocytochemical identification of oxyphilic mitochondrion-rich cells. Appl Immunohistochem. 1994;2: 261-267.

24. Yoshida J, Tanimura A, Yamashika H, Matsno K. Signet ring cell adenoma of the thyroid with mucinous predominance. Thyroid. 1999;9:401-404.

25. Bocker W, Dralle H, Kock G, de Heeder K, Hagemann J. Immunohistochemical and electron microscope analysis of adenomas of the thyroid gland. II. Adenomas with specific cytological differentiation. Virchows Arch. 1978;380: 205-220.

26. Johnson TL, Lloyd RV, Burney RE, Thompson NW. Hürthle cell thyroid tumors. An immunohistochemical study. Cancer. 1987:59:107-112.

27. Chetty R. Hürthle cell neoplasms of the thyroid gland: an immunohistochemical study. Histopathology. 1990;17:368-370.

28. LiVolsi VA, Brooks RV, Arendsh-Durand B. Anaplastic thyroid tumors: immunohistology. Am J Clin Pathol. 1987;87:434-442.

29. Swamy Venkatesh YS, Ordonez NG, Schultz PN, et al. Anaplastic carcinoma of the thyroid. A clinicopathological study of 121 cases. Cancer. 1990;66: 321-330.

30. Adsay NV, Adair CF, Heffess CS, Klimstra DS. Intraductal oncocytic papillary neoplasms of the pancreas. Am J Surg Pathol. 1996;20:980-994.

31. Jyotheeswaran S, Zotalis G, Penmetsa P, Levea CM, Scoeniger LO, Shah AN. A newly recognized entity: intraductal "oncocytic" papillary neoplasm of the pancreas. Am J Gastroenterol. 1998;93:2539-2543.

32. Mendelsohn G. Signet-cell-simulating microfollicular adenoma of the thyroid. Am J Surg Pathol. 1984;8:705-708.

33. Rigaud C, Peltier F, Bogomoletz WV. Mucin producing microfollicular adenoma of the thyroid. J Clin Pathol. 1985;38:277-280.

34. Solcia E, Capella C, Fiocca R, Sessa F, La Rosa S, Rindi G. Disorders of the endocrine system. In: Ming SC, Goldman H, eds. Pathology of the Gastrointestinal Tract. 2nd ed. Baltimore, Md: Williams \& Wilkins; 1998:295-322. 